\title{
A CONTAMINAÇÃO EM SOLOS PROVOCADA PELA DISPOSIÇÃO DE RESÍDUOS SÓLIDOS NO MUNICÍPIO DE PIRAPOZINHO (SP)
}

\section{THE CONTAMINATION IN SOILS CAUSED BY SOLID WASTE DISPOSAL IN THE MUNICIPALITY OF PIRAPOZINHO (SP)}

Geraldo Augusto Maximiano Ferdin', Lucas Prado Osco², Isabela Marega Rigolin ${ }^{3}$.

${ }^{1}$ Universidade do Oeste Paulista - UNOESTE, Curso de Engenharia Ambiental, Presidente Prudente, SP.

E-mail: geraldoamferdin@gmail.com

RESUMO - Com o crescimento da população mundial e seu enorme consumismo, ocorreu também o aumento demasiado da geração de resíduos. O maior problema nisso é o seu destino e disposição final que atualmente, conforme a Política Nacional de Resíduos Sólidos (Lei 12.305/2010), deveriam ser os aterros sanitários. Ainda assim, municípios utilizam lixões, locais constituídos de forma inadequada, desprovidos de planejamento e adequação as normas técnicas. Para tanto, o objetivo do presente trabalho é expor a situação do lixão municipal de Pirapozinho - SP e apontar seus efeitos e possíveis contaminações no solo do entorno. Como metodologia adotada optouse por dividir as seguintes etapas: mapeamento da área, trabalho de campo e coleta e analises das amostras de solos em laboratório. Com as análises foi possível alcançar resultados que comprovam a contaminação direta da área ao redor do lixão. Assim, concluímos que o lixão tem alta influência na degradação da área ao seu entorno, apresentando indícios de contaminação em até aproximadamente 75 metros do perímetro do lixão.

Palavras-chave: Resíduos Sólidos; Meio Ambiente; Degradação; Poluição De Solo.

ABSTRACT - With the growth of world population and its enormous consumption, the waste generation was also increased. The biggest problem with it is the currently destination and final disposal that, according to the National Policy on Solid Waste (Law 12.305/2010), should be in sanitary landfills. Still, municipalities use garbage dump, an inappropriate local that doesn't have the adequate technical standards. Therefore, the objective of this work is to describe the situation of the garbage dump of Pirapozinho - SP, aiming the effects

Recebido em: 19/08/2015 Revisado em: 23/09/2015 Aprovado em: 24/09/2015 and possible contamination on the soil located at the surroundings of the area. The methodology adopted was divided on the following steps: mapping the area, fieldwork, and the collection and analysis of soil samples in laboratory. With the analyzes was possible to achieve results that proved the direct contamination of the area around the 
garbage dump. Thus, we conclude that the garbage dump has high influence on the degradation of the area and its surroundings, with indications of contamination by up to about 75 meters from the garbage dump perimeter.

Keywords: Solid Waste; Environment; Degradation; Soil Pollution. 


\section{INTRODUÇÃO}

Como o passar dos anos ocorreu o crescimento da população e dos centros urbanos. Com isso, a geração de resíduos também apresentou aumento significativo. Os resíduos se tornaram, cada vez mais, um problema para a sociedade, ocupando espaços e sendo descartados, muitas vezes, de maneira incorreta. Os lixões consistem-se em locais para depósito desse material, embora sejam uma forma de deposição ineficiente, desprovidos de planejamento e adequação às normas técnicas, podendo alterar e prejudicar o meio onde estão situados. A forma apropriada, conforme a Política Nacional de Resíduos Sólidos (PRNS) Lei 12.305/2010, para a disposição final de resíduos sólidos (ou melhor, rejeitos), consistem-se nos aterros sanitários.

De acordo com Boscov (2008), os aterros sanitários consistem em um sistema previamente preparado para a deposição de rejeitos (lixo inservível), contando com componentes e práticas operacionais que apresentem uma série de técnicas de engenharia voltadas para a minimização dos impactos. Farias (2002) complementa a colocação de Boscov (2008), e enfatiza sobre questões como a impermeabilização da base, que tem por intuito isolar o material e impedir que o mesmo desenvolva contato com a camada de solo do local, os sistemas de drenagem, tanto periférica quanto superficial, de modo a isolar as águas pluviais e coletar o chorume (líquido produzido pela putrefação da matéria orgânica e lixiviação dos rejeitos), bem como a queima de gases produzidos durante $\mathrm{o}$ processo da biodegradação.

Ainda assim, apesar da técnica disponível, muitos municípios brasileiros optam por destinar seus resíduos sólidos para depósitos irregulares, como vazadouros, aterros em valas ou controlados, lixões a céu aberto, bota-foras, dentre outros que não se caracterizam como aterros sanitários. Não obstante, tais depósitos não oferecem proteção ao meio em que se encontram, impactando, dentre os recursos naturais adjacentes, o solo encontrado às suas proximidades. Para Giordano, Filho e Carvalho (2011) o chorume, ao incorporar no solo e subsolo local, representa um sério risco à sua condição, uma vez que percolado acumula concentrações de metais pesados, transportando o poluente pelo solo até um corpo d'água subterrâneo. Para tanto, o modo com que o contaminante percola por entre as camadas de solo encontra-se associado às suas características, físicas e biológicas.

O presente trabalho tem por objetivo analisar o lixão situado no município de Pirapozinho - SP e verificar o impacto de sua contaminação bem como a influência nos 
solos ao redor. A partir do mapeamento do alto curso da bacia hidrográfica do rio Pirapozinho, onde encontram-se presentes o lixão e a maior parcela da mancha urbana de Pirapozinho, foram realizadas analises de amostras do solo coletadas no entorno do lixão. A intenção por detrás dessas análises foi comprovar a contaminação do solo e, assim, indiretamente, demonstrar a influência na qualidade dos demais recursos naturais da área de estudo.

\section{METODOLOGIA}

Inicialmente foi realizado uma pesquisa bibliográfica para buscar um melhor entendimento do assunto e das técnicas utilizadas nas análises realizadas. 0 levantamento bibliográfico, também, permitiu a compreensão da dinâmica comportamental de infiltração do contaminante (no caso dos depósitos de resíduos sólidos, o chorume) em solos. Dentre as obras trabalhados destacam-se os trabalhos de Boscov (2008), Farias (2002), Giordano et al. (2011), Paschoalato, Blundi e Ferreira (2000), Celere et al. (2007), Zuquetti e Gandolfi (1991), Moreira, Lorandi e Moraes (2008), dentre outros.

Para o mapeamento foram utilizadas técnicas de geoprocessamento e sensoriamento remoto realizados por meio de interpretação visual a partir do software ArcGIS 10.2 sobre fotografias áreas com GSD
(Ground Sample Distance) de 1 metro e precisão planialtimétrica compatível com a escala 1:25.000, disponibilizadas pela EMPLASA (2010/2011). Esse mapeamento teve por intuito identificar as diversas feições antrópicas existentes no alto curso da bacia hidrográfica do rio Pirapozinho. Com a delimitação da bacia hidrográfica, deu-se início a vetorização das diversas características encontradas no interior da mesma. No mapeamento do uso e cobertura da terra foram identificadas as seguintes feições: áreas ú midas (correspondendo aos corpos d'água característicos da região, tais como freáticos em suspensão, lateral, planícies de inundação, além de outras), curso d'agua, propriedades rurais, vegetação arbórea nativa, mancha urbana e o depósito de resíduos sólidos.

O trabalho de campo constitui parte de um experimento científico e é a atividade realizada no local onde o fenômeno estudado ocorre naturalmente. Sendo assim optou-se por coletar amostras de solo ao redor da atividade poluidora (no caso, o lixão). O solo ao redor do lixão foi perfurado em cinco pontos diferentes, determinados anteriormente, para a coleta de 17 amostras que variavam em razão de sua mudança textural. Essas amostras consistiam-se em quatro amostras para o ponto um (1), quatro para o ponto dois (2), três para o ponto três (3), três para o ponto quatro (4) e três para o 
ponto cinco (5). Utilizou-se, para tal, o auxílio de um trado holandês de alumínio.

Cada amostra foi acondicionada individualmente em sacos plásticos, identificados para posteriormente serem analisados em laboratório. As amostras de solo foram encaminhadas ao laboratório da Universidade Estadual Paulista no Campus de Presidente Prudente para a realização de analise granulométrica, onde visa definir, para determinadas faixas pré-estabelecidas de tamanhos de grãos, a percentagem em peso que cada fração possui em relação à massa total da amostra em análise. Para essas análises foi utilizado uma adaptação da metodologia proposta pela EMBRAPA (1997). Uma vez obtida as análises físicas, destinaram-se as amostras de solo para o laboratório de solos da Universidade do
Oeste Paulista, onde realizaram-se análises químicas que permitiram a identificação das quantidades de macro e micronutrientes presentes nessas amostras. A metodologia empregada na análise química seguiu os princípios definidos por Raij et al. (2001).

\section{RESULTADOS}

A partir do processo de mapeamento foi produzido um mapa de uso e cobertura da terra, onde é apresentado as diversas características existentes no interior da bacia hidrográfica. A Figura 1, exibida adiante, representa o mapa elaborado. Convém destacar a localização dos pontos de coleta amostrados, que se encontram próximos ao perímetro do lixão. 
USO E COBERTURA DA TERRA NO ALTO CURSO DA BACIA HIDROGRÁFICA DO RIO PIRAPOZINHO (SP) - ANO DE 2011

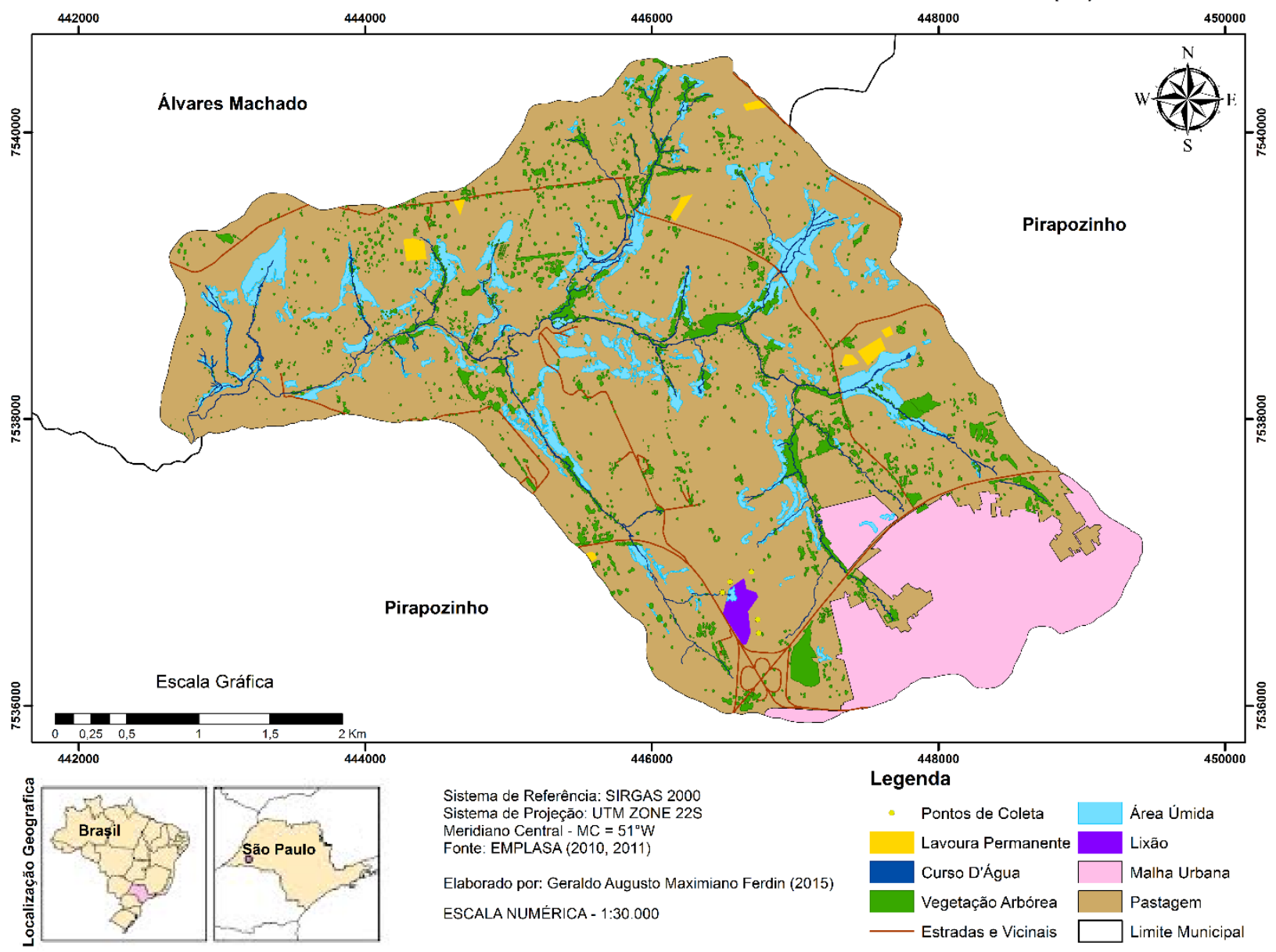

Figura 1. Uso e cobertura da terra do alto curso da bacia hidrográfica do rio Pirapozinho - SP.

Oliveira et al. (1999), em profundidades menores, próximas à mapeamento realizado na região, definiu a superfície. Na Tabela 1, localizada logo predominância de Argissolos Vermelho- abaixo, encontram-se os dados obtidos por Amarelos Eutróficos (PVa5) por toda a área meio da análise de granulometria dos cinco da bacia hidrográfica estudada. Esses solos pontos coletados ao redor do lixão. Essa apresentam menor espessura análise tornou possível elaborar a classe (aproximadamente 3 metros), permitindo a textural de cada uma das amostras, situadas concentração de água infiltrada em em diferentes profundidades. 
Tabela 1 - Granulometria dos Solos Coletados ao Redor do Lixão de Pirapozinho - SP

\begin{tabular}{|c|c|c|c|c|c|c|}
\hline Ponto & $\begin{array}{c}\text { Distância } \\
\text { do Lixão* (m) }\end{array}$ & $\begin{array}{c}\text { Profundidade } \\
\text { (cm) }\end{array}$ & $\begin{array}{c}\text { Areia } \\
\left(\mathrm{g} \mathrm{Kg}^{-1}\right)\end{array}$ & $\begin{array}{c}\text { Silte } \\
\left(\mathrm{g} \mathrm{Kg}^{-1}\right)\end{array}$ & $\begin{array}{c}\text { Argila } \\
\left(\mathrm{g} \mathrm{Kg}^{-1}\right)\end{array}$ & Classe Textural* \\
\hline \multirow{4}{*}{33} & \multirow{4}{*}{59,6} & 23.8 & 508,61 & 371,39 & 120 & Franco \\
\hline & & 44.4 & 611,745 & 287,255 & 101 & Franco Arenosa \\
\hline & & 58.4 & 706,025 & 207,975 & 86 & Franco Arenosa \\
\hline & & 71.1 & 639,11 & 289,89 & 71 & Franco Arenosa \\
\hline \multirow{4}{*}{34} & \multirow{4}{*}{63,4} & 25.4 & 893,665 & 74,335 & 32 & Areia Franca \\
\hline & & 50.8 & 500,32 & 361,68 & 138 & Franco \\
\hline & & 58.4 & 465,04 & 338,96 & 196 & Franco \\
\hline & & 74.9 & 450,46 & 370,54 & 179 & Franco \\
\hline \multirow{3}{*}{35} & \multirow{3}{*}{73,2} & 22.8 & 770,5 & 84,5 & 145 & Franco Arenosa \\
\hline & & 63.5 & 622,76 & 89,24 & 288 & Franco Argilo-Arenosa \\
\hline & & 78.7 & 612,365 & 103,635 & 284 & Franco Argilo-Arenosa \\
\hline \multirow{3}{*}{36} & \multirow{3}{*}{40,1} & 24.1 & 651,23 & 112,77 & 236 & Franco Argilo-Arenosa \\
\hline & & 40.6 & 614,44 & 107,56 & 278 & Franco Argilo-Arenosa \\
\hline & & 50.8 & 593,01 & 146,99 & 260 & Franco Argilo-Arenosa \\
\hline \multirow{3}{*}{37} & \multirow{3}{*}{43,9} & 29.2 & 797,26 & 66,74 & 136 & Franco Arenosa \\
\hline & & 40.6 & 809,69 & 63,31 & 127 & Franco Arenosa \\
\hline & & 63.5 & 665,72 & 163,28 & 171 & Franco Arenosa \\
\hline
\end{tabular}

* Refere-se à menor distância entre o ponto coletado e o perímetro do lixão.

** Classificado conforme o Diagrama de Classes Texturais - U.S.D.A (1951).

Em relação aos resultados obtidos por meio da análise química de macro e micronutrientes dos pontos coletados, os mesmos encontram-se dispostos na Tabela 2, apresentada logo a seguir. Os diferentes teores encontrados pautam-se nos níveis de recomendações para solos de Raij et al. (2001). Para tanto, optou-se por destacar na Tabela 2 os resultados que revelaram concentrações de compostos com valores acima daquilo sugerido. 
Tabela 2. Macro e Micronuentres Encontrados nas Amostras Coletadas ao Redor do Lixão de Pirapozinho - SP

\begin{tabular}{|c|c|c|c|c|c|c|c|c|c|c|c|c|c|c|c|c|}
\hline Ponto & Profundidade $(\mathrm{cm})$ & $\begin{array}{c}\mathrm{pH} \\
\left(\mathrm{CaCl}^{2}\right)\end{array}$ & $\begin{array}{l}\text { Matéria Orgânica } \\
\text { (M. O.) } \\
\end{array}$ & $\begin{array}{l}\text { Carbono } \\
\text { Total @ } \\
\end{array}$ & $\begin{array}{c}\text { Fósforo } \\
\text { (P) }\end{array}$ & $\begin{array}{l}\text { Acidez Potencial } \\
(\mathrm{H}+\mathrm{Al})\end{array}$ & $\begin{array}{c}\text { Potássio } \\
\text { (K) }\end{array}$ & $\begin{array}{c}\text { Cálcio } \\
\text { (Ca) }\end{array}$ & $\begin{array}{c}\text { Magnésio } \\
\text { (Mg) }\end{array}$ & SB & СTC & $\begin{array}{l}V \\
(\%)\end{array}$ & $\begin{array}{c}\text { Cobre } \\
(\mathrm{Cu})\end{array}$ & $\begin{array}{l}\text { Ferro } \\
(\mathrm{Fe})\end{array}$ & $\begin{array}{c}\text { Manganês } \\
\text { (Mn) }\end{array}$ & $\begin{array}{c}\text { Zinco } \\
(\mathrm{Zn})\end{array}$ \\
\hline \multirow{4}{*}{33} & 23.87 & 5,1 & 18,3 & 10,7 & 4,3 & 26,9 & 2,3 & 56,2 & 29,9 & 88,4 & 115,3 & 76,7 & 0,8 & 43,6 & 6,2 & 0,9 \\
\hline & 44.45 & 5,2 & 12,6 & 7,3 & 2,8 & 24,2 & 2,4 & 51 & 26,1 & 79,5 & 103,7 & 76,7 & 0,7 & 25,1 & 6,2 & 0,2 \\
\hline & 58.42 & 5,3 & 8,4 & 4,9 & 1,7 & 21,8 & 2,4 & 31 & 12,5 & 46 & 67,7 & 67,9 & 1,1 & 17,9 & 19 & 0,4 \\
\hline & 71.12 & 5,3 & 7,7 & 4,4 & 1,7 & 25,5 & 2,9 & 37,1 & 13,6 & 53,6 & 79,1 & 67,8 & 0,7 & 14,4 & 11,8 & 0,3 \\
\hline \multirow{4}{*}{34} & 25.40 & 6,2 & 4,5 & 2,6 & 12,8 & 10,4 & 3,2 & 40,8 & 21,6 & 65,6 & 76 & 86,3 & 0,5 & 29,1 & 3,2 & 0,6 \\
\hline & 50.80 & 6,4 & 8,9 & 5,2 & 28,3 & 12,9 & 4,5 & 79,7 & 45,5 & 129,6 & 142,4 & 91 & 1,3 & 48,7 & 4 & 2,1 \\
\hline & 58.42 & 6,3 & 20,7 & 12 & 23,9 & 17,6 & 5,8 & 120,4 & 60,7 & 186,9 & 204,5 & 91,4 & 1,7 & 45,7 & 6 & 2,2 \\
\hline & 74.93 & 6,3 & 12,8 & 7,5 & 19 & 17,6 & 4,9 & 96,7 & 56 & 157,6 & 175,2 & 89,9 & 1,3 & 33,6 & 6,2 & 1,2 \\
\hline \multirow{3}{*}{35} & 22.86 & 5,6 & 11,6 & 6,7 & 1,9 & 19,6 & 3,5 & 32,4 & 12,1 & 48 & 67,7 & 71 & 1,1 & 24,1 & 10,9 & 0,2 \\
\hline & 63.50 & 5,9 & 9,7 & 5,7 & 1,5 & 16,7 & 4,5 & 43,5 & 17,3 & 65,3 & 82 & 79,6 & 0,8 & 11,3 & 6 & 0,1 \\
\hline & 78.74 & 6,2 & 7,7 & 4,4 & 2,4 & 13,6 & 4,5 & 37,8 & 18,8 & 61 & 74,6 & 81,8 & 0,9 & 7,4 & 2,6 & 0,2 \\
\hline \multirow{3}{*}{36} & 24.13 & 6,5 & 9,5 & 5,5 & 1,9 & 11 & 6,5 & 37,8 & 21,3 & 65,6 & 76,6 & 85,6 & 0,8 & 8 & 1,8 & 1,7 \\
\hline & 40.64 & 6,8 & 5 & 2,9 & 0,6 & 9,4 & 8,3 & 32,3 & 18,1 & 58,6 & 68 & 86,2 & 0,6 & 4,2 & 0,9 & 0,3 \\
\hline & 50.80 & 5 & 3,2 & 1,9 & 0,4 & 9,9 & 8,6 & 35,1 & 20,7 & 64,4 & 74,3 & 86,7 & 0,5 & 2,1 & 0,2 & 0,1 \\
\hline \multirow{3}{*}{37} & 29.21 & 6,6 & 29,5 & 17,2 & 156,6 & 15,1 & 4,3 & 61,1 & 13,2 & 78,6 & 93,7 & 83,9 & 46 & 37,2 & 2,6 & 24,5 \\
\hline & 40.64 & 6,8 & 30,3 & 17,6 & 207,6 & 11,6 & 6,3 & 72,5 & 10,9 & 89,7 & 101,3 & 88,5 & 22,3 & 27,4 & 3,6 & 8,9 \\
\hline & 63.50 & 7,2 & 12,3 & 7,2 & 56 & 9,4 & 6 & 55,6 & 15,1 & 76,8 & 86,2 & 89,1 & 4,4 & 9,7 & 1,7 & 3 \\
\hline
\end{tabular}

Classes de Teores (Macronutrientes):

- $\quad \mathrm{P}\left(\mathrm{mg} \mathrm{dm}^{-3}\right)$ (Anual): 0 - 6 (Muito Baixo), 7-15 (Baixo), 16-40 (Médio), $41-80$ (Alto), > 80 (Muito Alto)

- $\quad \mathrm{K}\left(\mathrm{mmol}_{\mathrm{c}} \mathrm{dm}^{-3}\right): 0-0,7$ (Muito Baixo), 0,8-1,5 (Baixo), 1,6-3,0 (Médio), 3,1-6,0 (Alto), > 6,0 (Muito Alto);

- $\quad \mathrm{Ca}\left(\mathrm{mmol}_{\mathrm{c}} \mathrm{dm}^{-3}\right): 0-3$ (Baixo), $4-7$ (Médio), > 7 (Alto);

- $\quad \mathrm{Mg}\left(\mathrm{mmol}_{\mathrm{dm}} \mathrm{m}^{-3}\right): 0-4$ (Baixo), 5-8 (Médio), $>8$ (Alto)

- Sat. Bases (V): 0 - 25 (Muito Baixo), 26-50 (Baixo), 51- 70 (Médio), 71 - 90 (Alto), > 90 (Muito Alto);

- $\mathrm{pH}\left(\mathrm{CaCl}^{2}\right):<4,3$ (Muito Baixo), 4,4-5,0 (Baixo), 5,1-5,5 (Médio), 5,6-6,0 (Alto), > 6,0 (Muito Alto)

Classes de Teores (Micronutrientes):

- B (Água Quente): $0-0,20$ (Baixo), 0,30-0,80 (Médio), >0,80 (Alto);

- $\mathrm{Cu}\left(\mathrm{mg} \mathrm{dm}^{-3}\right): 0-0,20$ (Baixo), 0,30-0,80 (Médio), >0,80 (Alto)

- $\mathrm{Fe}\left(\mathrm{mg} \mathrm{dm}^{-3}\right): 0-4$ (Baixo), 5-12 (Médio), $>12$ (Alto);

$\operatorname{Mn}\left(\mathrm{mg} \mathrm{dm}^{-3}\right): 0-1,2$ (Baixo), 1,3 - 5,0 (Médio), >5,0 (Alto);

- $\quad \mathrm{Zn}\left(\mathrm{mg} \mathrm{dm}^{-3}\right): 0-0,50$ (Baixo), 0,6-1,2 (Médio), > 1,2 (Alto).

Metodologia Aplicada: Análise Química para Avaliação de Fertilidade de Solos Tropicais. Raij et al. (2001). Instituto Agronômico de Campinas (IAC). 285 p.

Colloquium Exactarum, v. 7, n.3 , Jul-Set. 2015, p.01-11. DOI: 10.5747/ce.2015.v07.n3.e123 


\section{DISCUSSÃO}

A partir do mapa elaborado é possível ressaltar a localização do lixão próximo a cidade de Pirapozinho, bem como de recursos encontrados nas suas adjacências. A situação observada no lixão de Pirapozinho

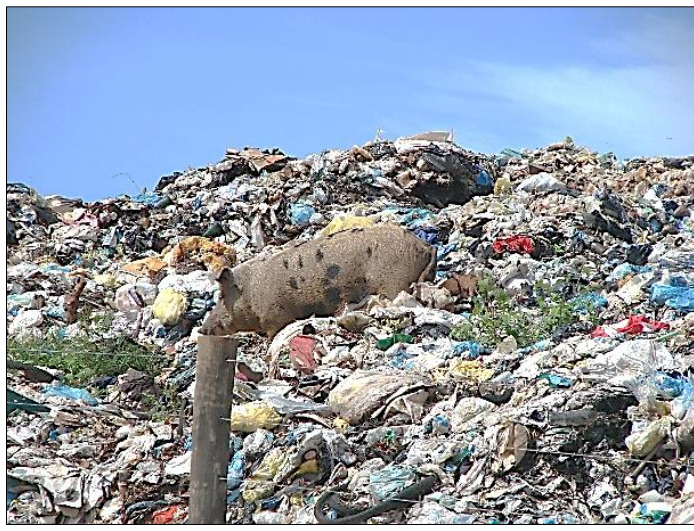

Figura 2 e 3. Depósitos de resíduos sólidos de Pirapozinho (SP) e área próxima ao lixão.

Os pontos de solos coletados,

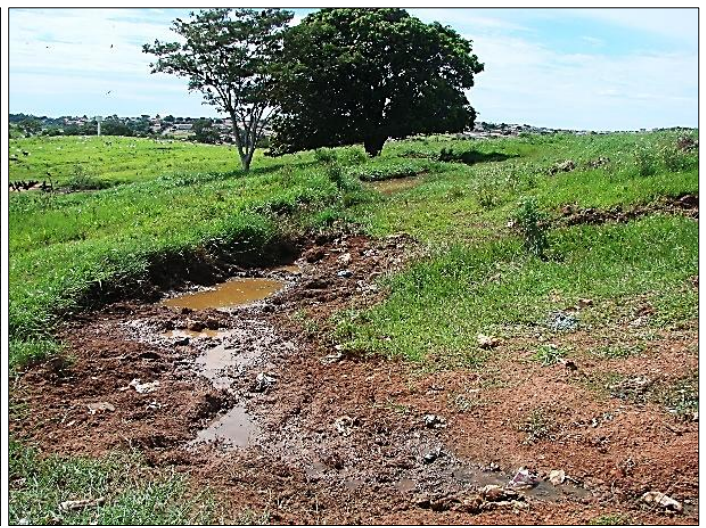
impactos advindos da atividade com os resultados encontrados durante as análises realizadas 


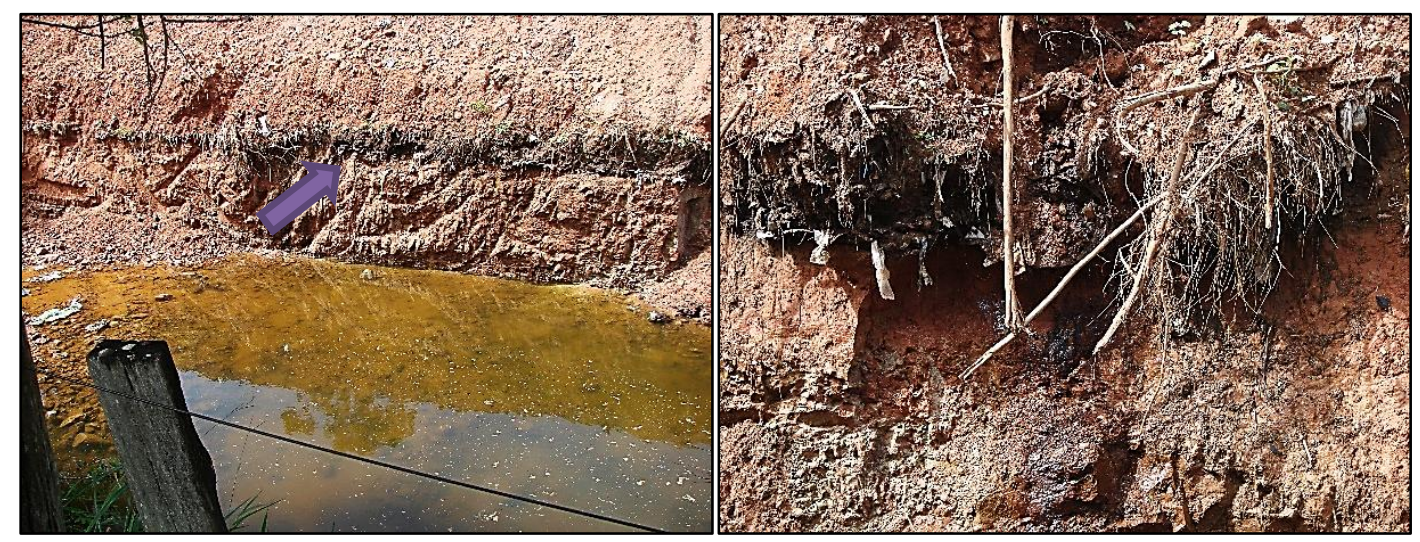

Figura 3 e 4. Lençol freático exposto pela abertura de vala para o depósito de resíduos sólidos.

Os resíduos sólidos descartados sobre essa área revelam o descaso da situação local, uma vez que a contaminação do corpo d'agua é explícita, pois a camada de resíduo compactado, logo acima do freático, coincide com o afloramento do recurso hídrico. Diante disso, é evidente que a camada de solo não suporta este tipo de atividade altamente impactante, uma vez que é pouco espessa e de baixa capacidade de atenuação do contaminante.

\section{CONCLUSÃO}

O presente trabalho abordou a situação local do lixão municipal de Pirapozinho - SP e sua contaminação no solo no entorno. A partir dos resultados obtidos pelas análises químicas e físicas dos pontos coletados, observou-se uma evidente degradação na área, afetando e modificando o solo encontrado. Outra condição de destaque seria o impacto ocasionado sobre os recursos hídricos presentes na área, uma vez que o solo não possui características propicias à um suporte adequado para este tipo de atividade.

O resultado das análises apresentou indício de contaminação em até aproximadamente 75 metros do perímetro do lixão. Com esse estudo pôde-se certificar e afirmar que o lixão não é apenas um local totalmente alterado e contaminado, mas que também estabelece influência em uma vasta parte da área ao seu redor, impactando os recursos naturais existentes. O estudo é de fundamental importância para diagnóstico da área, e trabalhos futuros por meio de análises mais específicas e o detalhamento mais aprofundado do local podem permitir a compilação de dados essenciais para o encerramento da área e o início de um estudo voltado para a escolha de um local mais apropriado para a destinação dos resíduos sólidos produzidos no município. 


\section{REFERÊNCIAS}

BOSCOV, M. E. G. Geotecnia ambiental. São Paulo: Oficina de Textos, 2008.

CELERE, M. S. et al. Metais presentes no chorume coletado no aterro sanitário de Ribeirão Preto, São Paulo, Brasil, e sua relevância para saúde pública. Cad. Saúde Pública, Rio de Janeiro, abr., 2007.

EMBRAPA. Centro Nacional de Pesquisa de Solos (CNPS). Manual de métodos de análise de solos. 2. ed. Rio de Janeiro, 1997. 212p. II. (EMBRAPA - CNPS. Documentos, 1).

FARIAS, F. S. Índice da qualidade de aterros de resíduos urbanos. 2002. Tese (Doutorado) - Universidade Federal do Rio de Janeiro.

GIORDANO, G.; FILHO, O. B.; CARVALHO, R. J. Processos físico-químicos para tratamento do chorume de aterros de resíduos sólidos urbanos. 1. ed. Rio de Janeiro, 2011. v.4.

MOREIRA, M. A. A.; LORANDI, R.; MORAES, M. E. B. Caracterização de áreas preferenciais para a instalação de aterros sanitários no município de Descalvado (SP), na escala 1:50.000. Revista Brasileira de Cartografia, n.60/02, 2008.

OLIVEIRA, J. B. et al. Empresa Brasileira de Pesquisa Agropecuária - EMBRAPA. Mapa Pedológico do Estado de São Paulo: legenda expandida. Campinas: Instituto agronômico; Rio de Janeiro: Embrapa solos, 1999.

PASCHOALATO, C. F. P. R.; BLUNDI, C. E.; FERREIRA, J. F. Caracterização dos líquidos percolados gerados por disposição de lixo urbano. In: CONGRESSO INTERAMERICANO DE ENG. SANITÁRIA E AMBIENTAL, 26.

Anais... Porto Alegre, 2000.

RAIJ, B. et al. Análise química do solo para avaliação da fertilidade de solos tropicais. Campinas: Instituto Agronômico, 2001. p.177-80.
SOIL SURVEY STAFF. Soil survey manual. United States: Department of Agriculture, 1951. (Handbook 18).

ZUQUETTE, L.V.; GANDOLFI, N. Problems and rules to select the landfill waste disposal sites Brazil. In: SYMPOSIUM INTERNATIONAL SUR LA GEOLOGIE URBAINE. Proceedings... Sfax, Tunisie, 1991. 